Boise State University

ScholarWorks

10-1-2009

\title{
Correcting Sample Selection in FARS Data to Estimate Seatbelt Use
}

Samia Islam

Boise State University

Frank Goetzke

University of Louisville

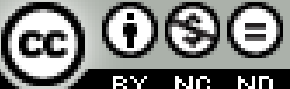

This is an author-produced, peer-reviewed version of this article. (C) 2009, Elsevier. Licensed under the Creative Commons AttributionNonCommercial-NoDerivatives 4.0 International License (https://creativecommons.org/licenses/by-nc-nd/4.0/). The final, definitive version of this document can be found online at Journal of Safety Research, doi: 10.1016/j.jsr.2009.09.002 


\title{
Correcting Sample Selection in FARS data to Estimate Seatbelt Use
}

\author{
Samia Islam ${ }^{a, *}$ and Frank Goetzke ${ }^{\mathrm{b}}$ \\ a: Assistant Professor, Department of Economics, Boise State University, Boise, ID 83725-1620, \\ *: Corresponding author. Email: samiaislam@boisestate.edu \\ ${ }^{\mathrm{b}}$ : Assistant Professor, Department of Urban and Public Affairs, University of Louisville, Louisville, KY \\ 40208
}

\begin{abstract}
In this paper, we use 2006 FARS data to estimate seatbelt use in the United States. We apply a method to correct the FARS data for sample selection bias introduced by Levitt and Porter (2001), as well as discuss the advantages of using FARS data for seatbelt analysis. Furthermore, based on assumptions of independence for seatbelt choice, we establish a lower and upper bound for seatbelt usage rates, and that once we correct for sample selection bias, the seatbelt usage estimates from the corrected FARS emerge at least as a comparable alternative to NOPUS estimates. This implies that researchers can use corrected FARS to complement NOPUS, thus being able to utilize the rich crosssectional details available in FARS data to analyze various relevant research questions.
\end{abstract}

\section{Introduction}

Every 14 seconds someone is injured, and every 12 minutes someone is killed in a crash on American roads. Highway crashes cost Americans at least $\$ 230.6$ billion a year, about $\$ 820$ per person (NHTSA, 2003, 2007). Over the past couple of decades, seatbelt usage rates in the United States have been improving as primary seatbelt laws become more common and as more vehicle users recognize their potential to lessen the extent of injury and prevent fatalities. Most research and government evaluations continue to support their effectiveness in fatality reduction overall and have found them to be about $45 \%$ effective in preventing fatalities (Evans, 1986, Partyka, 1988, and Blincoe, 1994) ${ }^{1}$. In 2006, eighty one percent of automobile occupants used seatbelts in the United States, based on statistics obtained from the annual National Occupant Protection Use Survey (NOPUS) which has been conducted since 1994. And yet, according to the National Highway Traffic Safety Administration (NHTSA) of the U.S. Department of Transportation, over half of passenger vehicle occupants killed in traffic accidents in 2006 died unbuckled (NHTSA, 2007).

NOPUS is an annual survey providing the only probability-based observed data on seatbelt use in the United States conducted by the National Center for Statistics and Analysis of the NHTSA who consider it to be their most reliable data set tracking the trends in seatbelt usage by motorists. However, NOPUS data has limitations precisely because it is observational. For instance, observations are made either while standing at the roadside or, in the case of expressways, while riding in a vehicle in traffic. This is considered a superior alternative to stopping vehicles and directly interviewing occupants because that

\footnotetext{
${ }^{1}$ It is, however, acknowledged that in rare cases safety devices such as seatbelts and air bags can cause injury, and are even fatal at times (Hollands, et al, 1996; Morris and Borja, 1998)
} 
could taint the behavior of motorists. However, observations made in a split second on occupants of swiftly moving vehicles - or at times, while driving in traffic oneself - place limits on data reliability, given the considerable scope for human error on the part of the observers.

The other more comprehensive data base available to evaluate highway safety practices as well as measure the effectiveness of vehicle safety devices is the Fatality Analysis Reporting System (FARS). This national census of motor vehicle fatalities is widely used by federal agencies and academics analyzing highway safety. FARS data has been collected since 1975 and contains information on over 989,451 motor vehicle fatalities within the 50 States, the District of Columbia, and Puerto Rico as well as over 100 different coded data elements that characterize the crash, the vehicle, and the people involved.

A critical problem with FARS data is that it underestimates seatbelts usage when compared to estimates obtained from observational data such as NOPUS (Salzberg, et al., 2002) due to the nature of the reporting system resulting in a sample selection bias. To be included in FARS, a crash must result in the death of a person (occupant of a vehicle or a non-occupant) within 30 days of the crash. Since it only lists those crashes where there is at least one fatality, the problem of sample selection becomes obvious. Sample selection arises because a given individual's seatbelt usage affects his or her probability of death, which in turn influences whether the crash is included in the data. It has been shown conclusively that such sample selection leads to biased estimation (Angrist and Krueger, 1999; Heckman, 1979; Heckman, et al., 1996). The extent of the estimation bias becomes even more significant when we consider the fact that about $0.5 \%$ of motor vehicle crashes involve a fatality and in $90 \%$ of the incidents, there is a single death (NHTSA, 1998). Had that death not occurred, the crash would not be included in the FARS data base. Therefore, empirically the impact of sample selection can be substantial, and failing to account for it leads to estimates that systematically understate seatbelt usage

Much of the earlier interest in seatbelt usage was in estimating their effectiveness in saving lives (Partyka, 1988; Partyka and Womble, 1989; Blincoe, 1994 and Klein and Walz, 1995). Recently, Salzberg et al. (2002) investigated seatbelt usage rates by comparing FARS data with observation surveys and concluded that unbelted occupants are over-represented in fatal collisions for two reasons: (a) because of a greater chance of involvement in potentially fatal collisions in the first place, and (b) because they are not afforded the protection of seatbelts when a collision does occur. Their model focused on risk but they did not address the sample selection bias.

Levitt and Porter (2001) use a simple but ingenious identification strategy that allows them to directly estimate the impact of seatbelts and air bags on crash survival rates, despite sample selection in the data. Seatbelts and air bags affect the probability of death, which consequently determines whether a crash is included in the FARS data set or not. As long as anyone else dies in the crash, it is included in the FARS data regardless of what happens to others in the crash. Focusing on this subset of crashes corrects the sample selection bias. Curiously but rather insightfully, the sample selection problem that arises because of the exclusion of a majority of non-fatal crash statistics from the FARS data set is countered by further limiting the data.

In this paper, we primarily focus on Levitt and Porter's (2001) identification method to correct for sample selection bias in FARS - a rich data base that NHTSA has maintained since 1975 - to obtain a credible estimate of seatbelt usage in the U.S. Most recent studies on safety devices tend to focus on the technicalities of the methodology to arrive at a precise estimation of effectiveness, taking the seatbelt usage rates released in NOPUS as given. Research suggests that consumers who are risk averse - and therefore, typically the safer drivers on the roads - buy vehicles with safety devices (Fell and Nash, 1989; NHTSA, 1998; Levitt and Porter, 2001). At times, because of this endogeneity of vehicle choice, results are believed to overstate any correlation between safety devices and fatality reduction. These are important results with serious policy implications and, therefore, accurate estimation is critical.

Answers to a host of policy questions such as the effectiveness of seatbelt legislation in increasing the usage and thereby reducing highway fatalities rely on the surveyed data. However, NOPUS data is aggregated, and lacks data on characteristics of the driver, passengers, the vehicle and the road environment, whereas FARS provides very detailed disaggregated data. If the FARS database can be 
established as an acceptable and comparable alternative to the observational NOPUS data, then the additional cross-sectional details collected in FARS can be used to analyze various relevant research questions, such as modeling seatbelt usage as a function of personal and vehicle attributes, not to mention a possible re-estimation of past studies (Partyka, 1988; Partyka and Womble, 1989; Blincoe, 1994; Klein and Walz, 1995; Dee, 1998; and Salzberg et al. 2002). Using two different specifications, i.e., correction based on strict independence of seatbelt choice (specification 1), and correction based on strict dependence of seatbelt choice (specification 2) to eliminate the sample selection bias and ensure a random sample, we are able to present empirical evidence that NOPUS may be underestimating seatbelt usage. Additionally, these two specifications allow us to show that the characteristics of vehicles, roads and riders affect the extent of the independence of observations in the databases.

The remainder of this paper is organized as follows: Section 2 describes the databases, and specifications used for our analysis. Section 3 presents the results and discusses their implications. Section 4 presents a summary of our findings and outlines possible future extensions of the current paper. Tables and figures are included at the end of the paper.

\section{Data and Methodology}

For our analysis, we used the 2006 data from the Fatality Analysis Reporting system (FARS) compiled by the National Highway Traffic Safety Administration (NHTSA) ${ }^{2}$. We specifically focused on the following categories of vehicles and passengers for easy correspondence with the NOPUS data: (i) passenger cars (body type code $1-12)$, utility vehicles (14 - 19), mini vans (20), vans (21), and pick-up trucks (30 - 39), (ii) front seat passengers (seating position code 11 and 13), and (iii) people using no restraint system or lap belts or shoulder belts or both ${ }^{3}$. 'Day time' is considered to be the hours between 8 a.m. to 6 p.m., following NHTSA survey times.

The categories for expressways and surface streets are derived from the reported roadway functional class. We follow the classification for urban, suburban and rural roadways in combination with the city code. For example, the "suburban" category is defined as urban roadway outside of a city. Vehicles types 14 through 21 which include utility vehicles, mini vans and vans are combined in the "Vans \& SUVs" category.

In Table 1 we show the 2006 NOPUS data in column (1), as well as the results of three different specification of the 2006 FARS estimation. In column (2) of the table we present the estimates from the data set that includes all FARS observations, and, thus, does not correct for sample selection bias. This specification includes all 25,437 FARS observations and consistently underestimates when compared to the surveyed data from NOPUS. We provide this specification to demonstrate the extent of sample selection bias on seatbelt usage estimates if the FARS data base were to be used with no correction. A detailed explanation of the two other specifications that we used to correct for sample selection bias to different degrees follows:

\subsection{Specification 1: Correction assuming independence of seatbelt choice}

Column (3) in Table 1 presents the estimates we refer to as "correction assuming independence of seatbelt choice". The sample size is 16,941. Based on the justification presented by Levitt and Porter (2001), it is safe to state that the FARS data set oversamples people without a seatbelt, since the lack of seatbelt will result in a higher probability of death. The single selection criterion that a crash is reported in the FARS data base is the occurrence of at least one fatality. Therefore, the data base is not a random sample of crashes; rather it is a self-selected sample of crashes with the selection criteria that at least one death has occurred. Since the selection criteria for fatality is correlated with seatbelt use, the data set cannot be considered a random sample for the purpose of effectively analyzing seatbelt use. However, if we assume independence of individual observations ${ }^{4}$, we can remove the record of the passengers who succumbed to a

\footnotetext{
${ }^{2}$ Source: http://www-fars.nhtsa.dot.gov/Main/index.aspx

${ }^{3}$ For reasonable comparison with NOPUS data, only passengers/vehicle occupants with shoulder belts or both shoulder and lap belts are considered to be using a seatbelt.

${ }^{4}$ Independence of observations imply that occupants in the same vehicle choose whether to use a seatbelt or not independently of each other.
} 
crash in all one-fatality crashes. The remaining observations then become a random sample, because all non-random observations, based on the selection criteria, are excluded. Crashes with more than one fatality can be seen as random because, from the perspective of the first fatality, the other fatality is random (not self-selected) and vice versa. The estimates from this specification reflect what we refer to as the 'lower bound' of possible seatbelt usage rates. This approach generally results in higher seatbelt usage rates than NOPUS. A detailed discussion of the results is provided in Section 3.

\section{2. $\quad$ Specification 2: Correction assuming dependence of seatbelt choice}

What if we cannot assume independence of observations in a car? Since seatbelt use of one person in a vehicle is highly correlated with the seatbelt use of the other occupant (Saibel and Salzberg, 1996; Nambisan and Vasudevan, 2007), we need to go a step further to remove the sample selection bias and to ensure a random sample. We refer to this second specification as "correction assuming dependence of seatbelt choice" in which we remove all the one-car crashes from the sample with the rationale that the likelihood of not using a seatbelt is not only higher for the killed person, but also for all other vehicle occupants. In addition, for every instance of a crash with only one fatality, we remove from the sample the vehicle in which this fatality occurred, based on the same argument, that the probability of not using the seatbelt is correlated both with the fatality as well as the other vehicle passengers. What remains in the final data set - with a sample size of 11,504 - are only the vehicles without fatalities as well as all vehicles from crashes where the fatalities occur in more than one vehicle because - as already explained in the previous section - from the point of view of either vehicle with a fatality, the other vehicle with a fatality is not selfselected. The results for this specification are shown in the last column of Table 1. As expected, the estimates are even higher than the results from the FARS data with correction assuming independence. However, assuming dependence of seatbelt choice may remove too many unbelted passengers from the sample due to their association with a fatality -- an event which has a higher probability of occurring precisely when vehicle occupants are unrestrained. Thus, the estimates from this specification reflect refer to as the 'upper bound' for seatbelt usage rates. This is relevant because research shows that seatbelt choice is not strictly independent in vehicles with more than one occupant (Saibel and Salzberg, 1996).

\section{$3 \quad$ Results and Discussion}

Table 1 presents NOPUS data for overall seatbelt use and seatbelt use for subgroups in column (1) and compares it with three different specification of FARS data reported in columns (2) through (4). As expected, FARS without correction in column (2) undercounts seatbelt use when compared to NOPUS in column (1). This is due to the previously discussed sample selection bias in FARS. Standard errors - which are small in magnitude - are also included in Table 1.

Column (3) presents the corrected estimates using specification 1 and implies independence of seatbelt usage choice, i.e., one occupant's choice does not influence that of other occupant(s). Column (4) assumes that the choice to use seatbelts is dependent or correlated across occupants of a vehicle and corresponds to specification 2. If seatbelt use is indeed strictly independent in reality, then both estimates of seatbelt usage, specification 1 and 2 should statistically be the same which is exactly what we find for the "Drivers, no passengers" category, (see Table 1). For most other categories, the estimates for each specification differ by some margin depending on the degree of independence. For example, if the category includes a large number of drive-alone vehicles, the margin between both estimates is expected to be small (around 5 percentage points), but if the opposite is true - such as in the categories of "Drivers with passengers", "Right-front passengers" and "Age 8-15" - the margin between both estimates almost doubles.

The magnitude of the each estimate from specification 2 is determined simultaneously by:

(a) the degree of dependence of observations

(b) how many risk-takers are in the remaining sample (after correction)

If risk-taking and fatality are not correlated (i.e., if there is no over-correction), then the upper bound would be the true usage rate and it would be determined solely by the degree of dependence in the observations. With the possibility of overcorrection, it could very well be that specification 2 includes fewer risk-takers than there are in reality, and as a result overestimates seatbelt use. 
Now, if we compare the lower bound result of FARS with the NOPUS data, we find that in almost 60 percent of all sub-categories, NOPUS seatbelt usage rate is lower than the FARS lower bound seatbelt usage rate, including the seatbelt usage rate for "All occupants". For some of the subcategories where that is not the case, (e.g., "With passenger", "Right-front passenger", "Age 8-15" and "Weekends"), it is clear that the observations are not independent. More than one occupant increases the likelihood that choices are correlated. Children are influenced by the behavior of accompanying adults. On weekends, more families are driving together. Therefore, the true result would be closer to the upper bound. The other categories that stand out are "Secondary enforcement law", "Pick-up trucks" and "Urban" for which the lower bound values are already more than 3 percentage points higher than the NOPUS values. The finding is not wholly unexpected, as it is quite possible that in an effort to minimize Type I errors (false positive), "conservative" roadside observers are more prone to committing Type II errors (false negative).

There can be another explanation for the comparatively higher magnitudes of the corrected FARS estimates, if we agree that reasonable predictions about the independence of seatbelt choice can be made for certain sub-categories. For instance, since "pickup truck" drivers are more likely to be driving alone, we can expect a greater degree of independence in their seatbelt choice. Yet, for this sub-category, the upper bound estimate is higher than the surveyed estimate by a wide margin. However, this finding may be explained by the high correlation between risk-taking and fatality for this sub-category of vehicles/users, and not the degree of dependence in the observations. Moreover, it also implies that pickup truck users take more risks generally because even after overcorrection, risk-takers are still well-represented. Likewise, in states with primary enforcement law, drivers are more likely to be using seatbelts regardless of what others are doing in order to avoid the penalties. Since primary enforcement law deters risky behavior, the correlation between risk-taking and fatality is expected to be low as well. In this case, the true estimate is closer to the lower bound. Using similar reasoning, we can comment on whether the true estimate is going to be closer to the upper or the lower bound for the rest of sub-categories as well.

It is important to note here that since risk-taking is correlated with seatbelt use ${ }^{5}$, and thus fatalities, using specification 2 may overcorrect the sample selection bias and push it to the opposite extreme compared to the results from FARS with no correction (column 2 in Table 1). Given our discussion so far, by now the reader will agree that whenever there is more than one person in a vehicle, seatbelt usage becomes a dependent event. However, at any given point in time on any U.S. road, there are also a sufficiently large number of people driving alone. Therefore, we believe that the correct seatbelt usage rate is anywhere in between both estimates, with specification 1 estimates (column 3 in Table 1) establishing the lower bound and specification 2 estimates (column 4 in Table 1) setting the upper bound. This is relevant for four of the sub-categories (e.g., "Vans and SUVs", "Motorists on expressways", "Age 16-24", and "South") for which the NOPUS estimate is higher than what we find with our lower bound specification but not quite close enough to the upper bound specification to indicate dependence of seatbelt choice. To a certain extent, these may be instances were road-side observers are committing Type I errors by letting pre-conceived notions regarding types of vehicles, roads and travelers bias the surveys. For these sub-categories, the true usage rate is expected to be somewhere in between the lower and the upper bound.

For the remaining sub-categories where dependence cannot be established as the reason for overestimation, our findings seriously raise the question whether NOPUS is undercounting seatbelt use. Even the lower bound estimates from FARS data using the strong assumption for strict independence of seatbelt choice to correct for sample selection bias suggest that more people wear seatbelts than found in the roadside surveys. This is clearly discernible from the graph in Figure 1. The 45-degree line represents all values where NOPUS estimates equal FARS estimates. The scatter plot clearly shows that generally the estimates from 'Spec 1' - although closer to the 45-degree line than either 'FARS-no correction' which is systematically underestimating due to sample selection bias or 'Spec 2' which has a tendency to

\footnotetext{
${ }^{5}$ It is well documented that certain driving behaviors, such as speeding, intentional risk taking, aggressive driving, and impaired driving are associated with increased risk of Moving vehicle collisions and that individuals engaging in high-risk behaviors are less likely to use belts than are low-risk persons (Evans and Wasielewski, 1983; Wasielewski, 1984; Preusser et al., 1991; Hunter et al. 1993; Winnicki, 1997 and Dee, 1998).
} 
overcorrect - lie above it. This suggests that road-side surveys may be under-sampling seatbelt use. Reasons could include poor visibility, high speeds of passing vehicles, and, especially in states with no primary seatbelt laws, a general bias on the part of the observers to err on the side of caution (Type II errors), especially in certain regions (Northeast), areas (urban) where more reckless driving is expected as well types of vehicles and drivers (pickup trucks).

Additionally, in Figure 1 we can see that the 'Spec 2' estimates converge towards the 'Spec 1' estimates the higher the surveyed NOPUS seatbelt rates are. This illustrates that the difference between the lower (Spec 1) and upper bound (Spec 2) estimates decreases at higher seatbelt use rates, which supports the hypothesis of fewer risk-takers in groups with higher rates of seatbelt use.

\section{Conclusion}

While the effectiveness of seatbelts is commonly recognized, U.S. seatbelt usage rates have been relatively low, especially compared to other developed nations. For years, the U.S. has trailed behind neighboring Canada in seatbelt usage rates even in states with mandatory seatbelt laws. In 1997, the federal government set targets to increase seatbelt usage from 68 percent in 1996 to 85 percent by 2000, and then 90 percent in 2005 , both of which went unachieved according to NOPUS data. Even as federal funding for highway safety initiatives and awareness programs rise, and primary and secondary law enforcement becomes more stringent at the state level, the failure to meet targeted usage rates is confounding. The results of the analysis presented in this paper suggest that, at least partially, the low usage rate may be explained by the fact that NOPUS is under-counting seatbelt users. Once we correct for sample selection, even the lower bound FARS estimates for a majority (more than 60 percent) of the sub-categories of vehicles and drivers indicate a higher rate of seatbelt usage in the U.S. when compared to the estimates from the observational NOPUS data. Although we cannot determine an exact estimate for seatbelt usage even with corrected FARS data, we find evidence in support of prior research that for the different sub-categories of vehicles, location, or occupant type, seatbelt usage is correlated with the degree of risk-taking (Salzberg, et al. 2002), as well as the dependence of seatbelt choice (Saibel and Salzberg, 1996; Nambisan and Vasudevan, 2007). However, it must be noted that the FARS data is not immune to additional bias. Fatal crashes are more likely to occur on highways with higher speeds, where it reasonable to assert that more vehicle occupants choose to buckle up. These same people could be less likely to wear a seatbelt when they are on suburban roads, say, for a quick trip to the grocery store. But this issue is easily addressed of by applying weights based on road classification and/or geography. In addition, it must be said, that the quality of the FARS data is only as good as the effort put in by the recording police officer. Since the police do not have any incentive for filling out the FARS form with care, there is some doubt about its overall accuracy. On the other hand, there is no reason for us to suspect a systematic bias. Accordingly, we have established in this paper that corrected FARS is overall at least as good at predicting seatbelt usage rates as NOPUS and therefore can be used as a credible alternative.

We acknowledge here that FARS is not the only alternative to NOPUS when it comes to crash and fatality data, but in many ways it is the most comprehensive, not to mention inexpensive and readily available. Our analysis and results are primarily an application of the Levitt and Porter (2001) methodology to address one specific problem with the FARS dataset - sample selection bias. Once sample selection is corrected following Levitt and Porter (2001), we show that FARS data can be used to estimate the effectiveness of seat belt usage. Our findings have implications for those earlier studies (mentioned in the introduction) that used uncorrected FARS data and likely presented biased results.

We consider our results especially significant given the rich cross-sectional detail available in the disaggregated FARS data base, which extends its potential for applicability in addressing and answering a myriad of policy questions in safety research. Future extensions of this paper will use methodologies established here to examine the extent to which seatbelt usage rates for states with primary seatbelt law compare to states without primary enforcement laws. 


\section{References}

Angrist, J. and Krueger, A. (1999) Empirical strategies in labor economics in Orley Ashenfelter and David Card (eds.), Handbook of Labor Economics, vol.3, ch.23, Amsterdam: Elsevier.

Blincoe L.J., (1994) Estimating the benefits from increased safety belt use. DOT HS, National Highway Traffic Safety Administration, Washington, DC, 808-133.

Cummings, P., Wells, J, D., Rivara, F. P. (2003) Estimating seat belt effectiveness using matched-pair cohort methods, Accident Analysis \& Prevention, 35(1), 143-149

Cummings, P., McKnight, B., and Weiss, N. S. (2003) Matched-pair cohort methods in traffic crash research, Accident Analysis \& Prevention, 35(1), 131-141,

Dee, T.S. (1998) Reconsidering the effects of seat belt laws and their enforcement status. Accident Analysis \& Prevention 30 (1998), pp. 1-10.

Evans, L. (1987) Estimating fatality reduction in safety belt use, Risk Analysis 7, 49-57.

Evans, L. (1986) The effectiveness of safety belts in preventing fatalities, Accident Analysis \& Prevention, $18,229-241$.

Evans, L. and Wasielewski, P. (1983) Risky driving related to driver and vehicle characteristics. Accident Analysis \& Prevention, 15, 121-136.

Fell, J. C. and Nash, C. E. (1989) The nature of the alcohol problem in U.S. fatal crashes, Health Education Quarterly, 16(3), 335-343.

Heckman, J. (1979) Sample selection bias as a specification error, Econometrica, 47(1), 153-161.

Heckman, J., Ichimura, H., Smith, J. and Todd, P. (1996) Sources of selection bias in evaluating social problems: an interpretation of conventional measures and evidence on the effectiveness of matching as a program evaluation method, Proc. Natl. Acad. Sci. USA, 93, 13416-13420.

Hollands, C.M., Winston, F.K., Stafford, P.W., and Shochat, S.J. (1996) Severe head injury caused by airbag deployment, Journal of Trauma, 41(5), 920-922.

Hunter, W.W., Stewart, R., Stutts, J. and Rodgman, E. (1993) Observed and self-reported seat belt wearing as related to prior traffic accidents and convictions, Accident Analysis \& Prevention, 25, 545-554.

Klein T.M. and Walz M.C., (1995) Research note: estimating lives saved by restraint use in potentially fatal crashes. National Highway Traffic Safety Administration, Washington, DC.

Levitt, S. and Porter, J. (2001) Sample Selection in the Estimation of Air Bag and Seatbelt Effectiveness, The Review of Economics and Statistics 83(4): 603-15.

Morris, M.S. and Borja, L. (1998) Letters to the editor, Journal of Trauma: Injury, Infection and Critical Care, 44, 238-239.

Nambisan, S. S. and Vasudevan, V. (2007) Is seatbelt usage by front seat passengers related to seatbelt usage by their drivers? Journal of Safety Research, 38(5): 545-55 
National Highway Traffic Safety Administration, Traffic Safety Facts 1997, Washington DC: NHTSA, 1998.

, Traffic Safety Facts 2002, Washington DC: NHTSA, 2003.

Traffic Safety Facts 2006, Washington DC: NHTSA, 2007.

Partyka, S.C., (1988) Lives saved by seat belts from 1983 through 1987. DOT HS 807 324. National Highway Traffic Safety Administration, Washington, DC.

Partyka S.C., and Womble K.B., (1989) Research notes: projected lives savings from greater belt use. National Highway Traffic Safety Administration, Washington, DC.

Preusser, D., Williams, A.F. and Lund, A.K. (1991) Characteristics of belted and unbelted drivers, Accident Analysis \& Prevention, 23, 475-482.

Rivara, F.P., Koepsell, T.D., Grossman, D.C. and Mock, C. (2000) Effectiveness of automatic shoulder belt systems in motor vehicle crashes, Journal of the American Medical Association, 283, 2826-2828.

Saibel C. and Salzberg P. (1996) The effect of seatbelt use on injury severity in motor vehicle collisions: a paired-comparison study, Washington Traffic Safety Commission, Olympia, WA

Salzberg, P., Yamada, A., Saibel, C. and Moffat. J. (2002) Predicting seat belt use in fatal motor vehicle crashes from observation surveys of belt use, Accident Analysis \& Prevention, 34(2), 139-148.

Wasielewski, P. (1984) Speed as a measure of driver risk: observed speeds versus driver and vehicle characteristics, Accident Analysis \& Prevention, 16, 89-103.

Winnicki, J. (1997) Analysis of ejection in fatal crashes, DOT HS 808 643, National Highway Traffic Safety Administration, Washington, DC. 
Figure 1: Comparison of FARS estimates using different specifications to correct for sample selection bias depending on NOPUS seatbelt rates

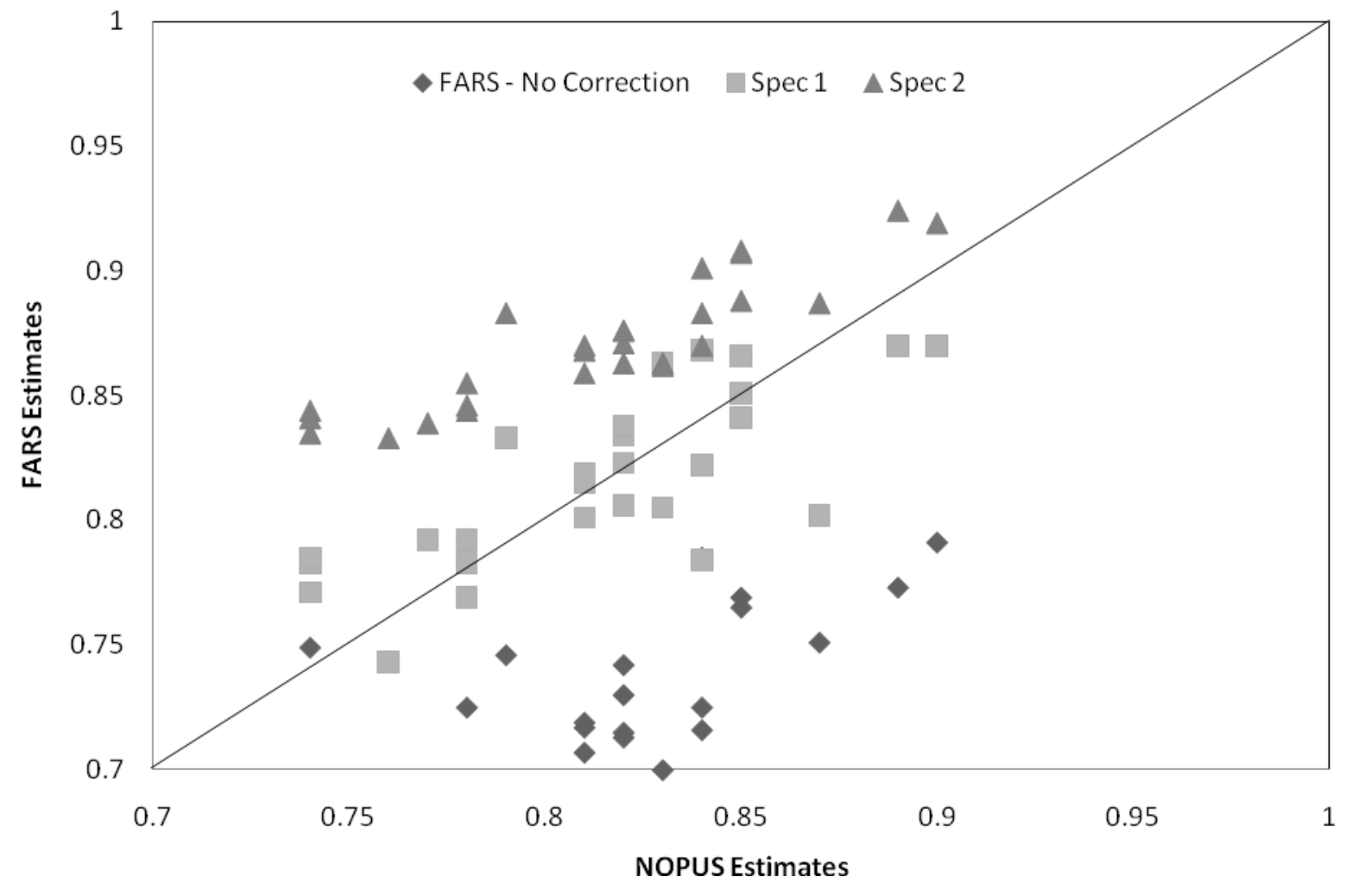


Table 1: Comparison of NOPUS seatbelt rates with FARS estimates using different specifications

\begin{tabular}{|c|c|c|c|c|c|c|}
\hline & $\begin{array}{c}(1) \\
\text { NOPUS } \\
2006\end{array}$ & $\begin{array}{c}\text { (2) } \\
\text { FARS } \\
\text { (no correction) }\end{array}$ & SE & $\begin{array}{c}\text { (3) } \\
\text { FARS } \\
\text { (independent) }\end{array}$ & SE & $\begin{array}{c}(4) \\
\text { FARS } \\
\text { (dependent) }\end{array}$ \\
\hline Sample size & & 25,437 & & 16,941 & & 11,504 \\
\hline All Occupants & $81 \%$ & $71.7 \%$ & $0.3 \%$ & $81.5 \%$ & $0.3 \%$ & $86.8 \%$ \\
\hline Males & $78 \%$ & $68.4 \%$ & $0.4 \%$ & $79.2 \%$ & $0.4 \%$ & $84.6 \%$ \\
\hline Females & $85 \%$ & $76.9 \%$ & $0.4 \%$ & $85.1 \%$ & $0.4 \%$ & $90.7 \%$ \\
\hline Driver & $82 \%$ & $71.5 \%$ & $0.3 \%$ & $83.4 \%$ & $0.3 \%$ & $87.1 \%$ \\
\hline No passengers & $83 \%$ & $69.3 \%$ & $0.4 \%$ & $86.3 \%$ & $0.4 \%$ & $86.3 \%$ \\
\hline With passengers & $87 \%$ & $75.1 \%$ & $0.5 \%$ & $80.2 \%$ & $0.5 \%$ & $88.7 \%$ \\
\hline Right-front passengers & $78 \%$ & $72.5 \%$ & $0.6 \%$ & $76.9 \%$ & $0.6 \%$ & $85.5 \%$ \\
\hline Age 8-15 & $84 \%$ & $72.5 \%$ & $1.7 \%$ & $78.4 \%$ & $1.7 \%$ & $88.3 \%$ \\
\hline Age $16-24$ & $76 \%$ & $65.3 \%$ & $0.7 \%$ & $74.3 \%$ & $0.7 \%$ & $83.3 \%$ \\
\hline Age 25-69 & $82 \%$ & $73.0 \%$ & $0.4 \%$ & $83.8 \%$ & $0.4 \%$ & $87.6 \%$ \\
\hline Age 70 and older & $85 \%$ & $76.5 \%$ & $0.7 \%$ & $86.6 \%$ & $0.8 \%$ & $90.8 \%$ \\
\hline Primary enforcement laws & $85 \%$ & $66.6 \%$ & $0.5 \%$ & $84.1 \%$ & $0.4 \%$ & $88.8 \%$ \\
\hline Secondary enforcement laws & $74 \%$ & $74.9 \%$ & $0.3 \%$ & $77.1 \%$ & $0.5 \%$ & $83.5 \%$ \\
\hline Motorists on expressways & $89 \%$ & $77.3 \%$ & $0.7 \%$ & $87.0 \%$ & $0.6 \%$ & $92.4 \%$ \\
\hline Motorists on surface streets & $81 \%$ & $70.7 \%$ & $0.3 \%$ & $80.1 \%$ & $0.3 \%$ & $85.9 \%$ \\
\hline Passenger cars & $82 \%$ & $74.2 \%$ & $0.4 \%$ & $82.3 \%$ & $0.4 \%$ & $87.6 \%$ \\
\hline Vans \& SUVs & $84 \%$ & $71.6 \%$ & $0.6 \%$ & $82.2 \%$ & $0.6 \%$ & $87.0 \%$ \\
\hline Pickup trucks & $74 \%$ & $65.6 \%$ & $0.6 \%$ & $78.3 \%$ & $0.7 \%$ & $84.4 \%$ \\
\hline Urban areas & $79 \%$ & $74.6 \%$ & $0.4 \%$ & $83.3 \%$ & $0.4 \%$ & $88.3 \%$ \\
\hline Suburban areas & $84 \%$ & $78.5 \%$ & $0.8 \%$ & $86.8 \%$ & $0.8 \%$ & $90.1 \%$ \\
\hline Rural areas & $78 \%$ & $68.0 \%$ & $0.4 \%$ & $78.3 \%$ & $0.5 \%$ & $84.4 \%$ \\
\hline Northeast & $74 \%$ & $68.8 \%$ & $0.9 \%$ & $78.5 \%$ & $1.0 \%$ & $84.1 \%$ \\
\hline Midwest & $77 \%$ & $69.7 \%$ & $0.6 \%$ & $79.2 \%$ & $0.7 \%$ & $83.9 \%$ \\
\hline South & $83 \%$ & $70.0 \%$ & $0.4 \%$ & $80.5 \%$ & $0.4 \%$ & $86.2 \%$ \\
\hline West & $90 \%$ & $79.1 \%$ & $0.6 \%$ & $87.0 \%$ & $0.5 \%$ & $91.9 \%$ \\
\hline Weekday & $81 \%$ & $71.9 \%$ & $0.3 \%$ & $81.9 \%$ & $0.4 \%$ & $87.0 \%$ \\
\hline Weekends & $82 \%$ & $71.3 \%$ & $0.5 \%$ & $80.6 \%$ & $0.5 \%$ & $86.3 \%$ \\
\hline
\end{tabular}

